\title{
Annual Report of the Korean Association of External Quality Assessment Service on Urinalysis and Fecal Occult Blood Testing (2019)
}

\author{
Chang-Ho Jeon, Sang-Gyung Kim, and Young-Cheol Bae \\ Department of Laboratory Medicine, School of Medicine, Daegu Catholic University, Daegu, Korea
}

\section{Corresponding author:}

Chang-Ho Jeon

Department of Laboratory Medicine, School of Medicine, Daegu Catholic University, 33 Duryugongwon-ro 17-gil, Nam-gu, Daegu 42472, Korea

Tel +82-53-650-4144

Fax +82-53-653-8672

E-mail chjeon@cu.ac.kr

This is an Open Access article distributed under the terms of the Creative Commons Attribution Non-Commercial License (http://creativecommons.org/licenses/ by-nc/4.0) which permits unrestricted non-commercial use, distribution, and reproduction in any medium, provided the original work is properly cited.
In 2019, external quality assessment trials for urinalysis and fecal occult blood (FOB) testing were conducted using data from 1,650 participants. Urine chemistry tests were performed thrice, while urine sediment and FOB tests were performed twice. Urine chemistry tests consisted of $\mathrm{pH}$, protein, glucose, ketone bodies, bilirubin, blood, urobilinogen, nitrite, leukocyte, and specific gravity analyses. The results of urine chemistry and specific gravity tests showed accuracy rates $>95 \%$, except for the $\mathrm{pH}$ test; however, in the few instruments, the accuracy rates of $\mathrm{pH}$, along with glucose, ketone, bilirubin, blood, urobilinogen, and leukocytes were $<50 \%$, suggesting matrix effects of quality control materials. The accuracy rates of urine sediment analyses were low, especially for contrast media, white blood cast, and broad casts. In contrast, the ability to differentiate between transitional and renal tubular epithelial was high. In the FOB quality test, reagents showed accuracy rates $>90 \%$, except for SD (Standard Diagnostics, Korea) and Humasis FOB reagents (Humasis Co., Korea). The accuracy rates of SD FOB reagents improved in the negative specimens. In the FOB quantitative test, the Alfresa NS-Plus $C$ instrument (Alfresa Pharma Co., Japan) showed high values in negative specimens; fortunately, its usage has declined.

(Lab Med Qual Assur 2020;42:157-165)

Key Words Quality control, Urinalysis, Occult blood, Accuracy

\section{서론}

요경검학분과의 2019년도 외부정도관리사업을 위하여 요화학 검사는 3 회 시행하였고 총 12 개의 관리물질을 사용하였다. 요침 사검사는 2회 시행하였으며 총 8 개의 사진을 게시하여 판독하도 록 하였다. 대변잠혈검사(fecal occult blood, FOB) 또한 2회 시 행하였으며 총 6 개의 관리물질을 사용하였다. 요화학검사 및 $\mathrm{FOB}$ 신빙도조사에는 국내에서 제조된 관리물질을 사용하였다.

2019년 신빙도조사사업 결과판정에서 반정량결과를 나타내는 검사항목은 결과값이 최빈도값 \pm 1 단계를 보이는 전체 기관 수가 전체 참여기관 수의 $80 \%$ 를 넘으면 정답으로 판정하였다. 2019년 도에는 특정 장비의 결과분포가 전체 결과분포와 상이하게 나타날
경우 제조회사 기준으로 판정하여 code 506을 사용하였다. Code 506 은 해당 기관이 사용하는 기기 및 시약에서는 합의된 결론이 도출되었으나 의도된 결과 또는 연관된 검사종목의 결과와 상이하 여 평가할 수 없는 경우이다. 참여기관은 1 차 $1,614,2$ 차 $1,645,3$ 차 1,656 기관이 각각 참여하여 2018년에 비하여 증가하였다.

\section{대상 및 방법}

\section{1. 대상}

요경검학분과에서는 대한임상검사정도관리협회에 등록된 기관 을 대상으로 2019년도 2월, 4월, 9월 3차에 걸쳐 정도관리물질을 발송하였다. 참여기관 수는 3차 조사에서 1,656기관으로 2018년 
도 동일 차수의 1,590 기관에 비하여 $4.0 \%$ 증가되었다.

\section{2. 재료}

요화학검사를 위한 관리물질은 1차(CU-19-01 04), 2차(CU19-05 08), 3차(CU-19-09 12) 검체 모두 국내에서 제조한 액상 관리물질 4종씩을 각 회원기관에 냉장 포장하여 발송하였다. 이 중 1차 및 3 차에는 본 협회 홈페이지에 게시한 요침사 사진 8 매 등 모두 20종의 검체를 우송 및 게시하여 정도관리 신빙도조사를 시 행하였다. 결과치의 입력은 본 협회에서 구축한 신빙도조사사업 홈페이지에서 직접 입력하는 방식을 사용하였다. $\mathrm{FOB}$ 를 위한 관 리물질도 1차 및 2차 검체 모두 국내에서 제조한 점액성 분말관리 물질 3종(CS-19-01-06)을 각 회원기관에 냉장 포장하여 발송하 였다.

\section{3. 정도관리물질의 허용치}

요화학 및 $\mathrm{FOB}$ 검사의 경우 주관 기관에서 실험한 참고치, 각 기관에서 회신한 결과의 일치도를 고려하였으며, 정성결과는 정 답이거나 참여기관의 $80 \%$ 일치를 보이는 결과로 하였다. 반정량 결과는 결과값이 최빈도값 \pm 1 단계를 보이는 전체 기관 수가 전 체 참여기관 수의 $80 \%$ 를 넘으면 정답으로 판정하였다. 정량결과 를 보이는 검사항목은 결과값이 기준분류에 대해 3 표준편차지수 (standard deviation index) 이내일 경우 정답으로 판정하였다.

\section{결과}

\section{1. 요화학검사 9종의 신빙도조사 성적}

요화학검사 9종 $(\mathrm{pH}$, protein, glucose, ketone, bilirubin, blood, urobilinogen, nitrite, leukocyte)의 신빙도조사 성적은

Table 1. Number of participants and acceptable rates in the urine chemistry QC

\begin{tabular}{lccc}
\multicolumn{1}{c}{ Tests } & 1st trial & 2nd trial & 3rd trial \\
\hline $\mathrm{pH}$ & $1,606(91.5)$ & $1,636(93.5)$ & $1,643(95.5)$ \\
\hline Protein & $1,614(98.3)$ & $1,645(94.7)$ & $1,656(98.4)$ \\
\hline Glucose & $1,608(99.3)$ & $1,639(99.2)$ & $1,630(98.1)$ \\
\hline Ketone & $1,560(97.7)$ & $1,590(94.5)$ & $1,594(97.9)$ \\
\hline Bilirubin & $1,558(97.9)$ & $1,588(97.7)$ & $1,595(98.8)$ \\
\hline Blood & $1,607(95.9)$ & $1,637(96.3)$ & $1,621(98.7)$ \\
\hline Urobilinogen & $1,560(99.3)$ & $1,590(99.3)$ & $1,597(97.3)$ \\
\hline Nitrite & $1,526(99.3)$ & $1,555(99.1)$ & $1,561(99.8)$ \\
\hline Leukocyte & $1,515(98.8)$ & $1,545(98.9)$ & $1,553(99.4)$ \\
\hline
\end{tabular}

Values are presented as number of participants (acceptable \%).
Table 1에 요약하였다. 모든 항목에서 $95 \%$ 이상의 정답률을 나 타내었으나 $\mathrm{pH}$ 항목은 1-2차에서 $95 \%$ 이하의 정답률을 나타내 었다.

\section{2. 요화학 분석기에 따른 요화학검사 신빙도조사 성적}

각 회사별 요화학 분석기에 따른 요화학검사의 신빙도조 사 성적은 Table 2와 같다. YD (YD Diagnostics, Yongin, Korea)가 39.8\%로 가장 많이 사용하고 있으며, SD (Standard Diagnostics, Seoul, Korea) 23.2\%, Roche (Roche, Mannheim, Germany) 14.3\%, DFI (DFI Co. Ltd., Gimhae, Korea) $9.1 \%$ 순이었다.

대부분의 장비에서 $90 \%$ 이상의 정답률을 보였으나, 회사별 장비에 따라 정답률에 다소 차이를 나타내어 일부 검사항목에서 는 $90 \%$ 이하의 정답률을 보였다. $\mathrm{pH}$ 항목은 Roche, Siemens (Siemens Healthcare, Erlangen, Germany) 및 DFI 제품 이 $90 \%$ 이하의 정답률을 나타내었고, glucose는 Beckman사 (Beckman Coulter Inc., Brea, CA), ketone은 Sysmex (Symex Co., Kobe, Japan), Eiken (Eiken Chemical Co., Tokyo, Japan) 및 Arkray (Arkray Inc., Kyoto, Japan)사, bilirubin은 Eiken 및 Beckman사, blood는 Sysmex, Eiken 및 Arkray사, urobilinogen은 Sysmex, Arkray 및 Beckmann사, leukocyte 은 Beckman사에서 각각 $90 \%$ 이하의 정답률을 나타내었다.

$90 \%$ 이하의 양성률을 보인 항목을 분석하기 위하여 신빙도 검체 및 제조회사별로 정답률을 조사하였다(Table 3). pH 항목 에서 $80 \%$ 이하의 양성률을 보이는 장비들이 가장 많았고, $15 \%$ (Roche) 및 44\% (DFI 및 Siemens)의 정답률을 보이기도 하 였다. Beckman사 장비는 glucose, bilirubin, urobilinogen, leukocyte의 항목에서 $0 \%-20 \%$ 의 정답률을 나타내었다. Sysmex사 장비는 ketone, blood, urobilinogen에서 2\%-35\%, Eiken사는 ketone, blood에서 3\%-5\%, Arkray사는 ketone, blood, urobilinogen에서 5\%-21\%의 정답률을 각각 나타내었다.

\section{3. 요화학 분석기로 시행한 요비중검사 신빙도조사 성적}

요비중검사는 굴절계 검사는 시행하지 않고 요화학 분석장비로 측정하였다. Table 4 에서와 같이 모든 검체에서 $95 \%$ 이상의 정답 률을 나타내었다. 그러나 결과 입력 시 잘못된 값이 입력되는 경우 가 발생하여 $0.01,0.025$ 등의 결과가 입력되었다. 각 기관에서 결 과 입력 시 주의가 필요하였다.

\section{4. 사진 검체를 이용한 요침사물 검사결과}

사진 검체를 사용하여 시행한 요침사물 신빙도조사의 정답 률은 $15.9 \%$ 에서 $93.0 \%$ 의 매우 넓은 정답률을 보였다(Figs. 
Table 2. Acceptable rates based on urine analyzers of different companies

\begin{tabular}{|c|c|c|c|c|c|c|c|c|c|c|}
\hline Instrument & No. (\%) & $\mathrm{pH}$ & Protein & Glucose & Ketone & Bilirubin & Blood & Urobilinogen & Nitrite & Leukocyte \\
\hline \multicolumn{11}{|c|}{ 1st proficiency test } \\
\hline YD & 594 (38.9) & 96.1 & 98.8 & 98.9 & 99.3 & 98.7 & 95.4 & 99.7 & 99.3 & 99.1 \\
\hline SD & $355(23.2)$ & 94.0 & 97.8 & 99.0 & 99.1 & 99.6 & 99.0 & 99.4 & 99.1 & 98.7 \\
\hline Roche & $218(14.3)$ & 91.9 & 96.8 & 100.0 & 99.1 & 98.3 & 98.2 & 98.6 & 99.4 & 99.7 \\
\hline DFI & $139(9.1)$ & 83.9 & 89.1 & 98.1 & 98.9 & 97.1 & 98.3 & 99.0 & 99.5 & 98.9 \\
\hline Siemens & $92(6.0)$ & 74.2 & 100.0 & 99.5 & 99.7 & 92.1 & 99.7 & 99.5 & 99.7 & 99.5 \\
\hline Sysmex & $59(3.9)$ & 100.0 & 100.0 & 100.0 & 75.4 & 100.0 & 75.4 & 100.0 & 100.0 & 100.0 \\
\hline Eiken & $37(2.4)$ & 91.9 & 98.8 & 100.0 & 76.4 & 89.9 & 75.6 & 100.0 & 100.0 & 100.0 \\
\hline Arkray & $23(1.5)$ & 95.7 & 97.9 & 98.9 & 98.9 & 96.8 & 100.0 & 98.9 & 100.0 & 100.0 \\
\hline Beckman & $10(0.7)$ & 100.0 & 100.0 & 100.0 & 100.0 & 75.0 & 95.0 & 97.5 & 100.0 & 75.0 \\
\hline \multicolumn{11}{|c|}{ 2nd proficiency test } \\
\hline YD & $636(39.8)$ & 96.8 & 99.5 & 99.5 & 94.8 & 98.0 & 96.8 & 99.5 & 99.3 & 99.0 \\
\hline SD & $370(23.2)$ & 94.0 & 98.3 & 99.0 & 95.8 & 98.8 & 97.8 & 98.8 & 99.0 & 98.5 \\
\hline Roche & $216(13.5)$ & 75.3 & 100.0 & 100.0 & 91.3 & 100.0 & 99.3 & 98.8 & 99.8 & 99.8 \\
\hline DFI & 145 (9.1) & 84.5 & 91.0 & 98.8 & 98.3 & 97.8 & 98.8 & 99.8 & 99.3 & 99.3 \\
\hline Siemens & $96(6.0)$ & 77.5 & 99.8 & 99.8 & 94.5 & 91.5 & 100.0 & 99.3 & 99.8 & 99.0 \\
\hline Sysmex & $65(4.1)$ & 99.5 & 100.0 & 100.0 & 99.0 & 100.0 & 75.5 & 100.0 & 100.0 & 100.0 \\
\hline Eiken & $38(2.4)$ & 92.5 & 99.3 & 100.0 & 99.3 & 90.8 & 78.3 & 100.0 & 100.0 & 100.0 \\
\hline Arkray & $22(1.4)$ & 97.8 & 100.0 & 98.8 & 76.1 & 100.0 & 100.0 & 99.0 & 99.0 & 99.0 \\
\hline Beckman & $10(0.6)$ & 100.0 & 100.0 & 77.5 & 100.0 & 77.5 & 100.0 & 97.5 & 100.0 & 75.0 \\
\hline \multicolumn{11}{|c|}{ 3rd proficiency test } \\
\hline YD & 615 (39.5) & 96.0 & 99.3 & 97.5 & 98.8 & 99.5 & 99.0 & 99.5 & 100.0 & 99.3 \\
\hline SD & $369(23.7)$ & 98.0 & 98.3 & 97.0 & 99.0 & 99.5 & 98.0 & 99.0 & 100.0 & 99.5 \\
\hline Roche & 201 (12.9) & 94.0 & 100.0 & 99.5 & 99.8 & 99.8 & 99.0 & 96.3 & 99.5 & 100.0 \\
\hline DFI & $139(8.9)$ & 96.3 & 91.3 & 99.8 & 99.0 & 98.8 & 99.0 & 99.0 & 100.0 & 98.5 \\
\hline Siemens & $100(6.4)$ & 78.8 & 100.0 & 100.0 & 97.5 & 95.3 & 100.0 & 95.0 & 100.0 & 100.0 \\
\hline Sysmex & $77(5.0)$ & 100.0 & 100.0 & 100.0 & 80.3 & 100.0 & 100.0 & 83.8 & 99.8 & 100.0 \\
\hline Eiken & $25(1.6)$ & 92.5 & 99.3 & 99.3 & 97.5 & 89.0 & 100.0 & 97.5 & 100.0 & 100.0 \\
\hline Arkray & $19(1.2)$ & 100.0 & 100.0 & 100.0 & 100.0 & 100.0 & 80.3 & 77.8 & 100.0 & 98.8 \\
\hline Beckman & $10(0.6)$ & 100.0 & 100.0 & 100.0 & 95.0 & 72.5 & 97.5 & 77.5 & 100.0 & 100.0 \\
\hline
\end{tabular}

Values are presented as number (\%). The results $<90 \%$ of accuracy were indicated in the bold type. The instruments used were from the following companies: YD (YD Diagnostics, Yongin, Korea), SD (Standard Diagnostics, Seoul, Korea), Roche (Roche Diagnostics, Mannheim, Germany), DFI (DFI Co. Ltd., Gimhae, Korea), Siemens (Siemens Healthcare, Erlangen, Germany), Eiken (Eiken Chemical Co., Tokyo, Japan), Symex (Symex Co., Kobe, Japan), Arkray (Arkray Inc., Kyoto, Japan), and Beckman (Beckman Coulter Inc., Brea, CA, USA).

1, 2, Table 5). Transitional epithelial cell (CUI-19-01), ammonium magnesium phosphate (CUI-19-03), uric acid (CUI-19-06) 및 calcium oxalate 결정(CUI-19-08)은 모두 87\% 이상의 정답률을 나타내었다.

Contrast media (CUI-19-02), white blood cell cast (CUI-
19-04) 및 broad cast (CUI-19-07)는 20\% 이하의 정답률을 나타 내었고, transitional epithelial cell (CUI-19-05)은 63\%의 정답 률을 나타내어 code 505로 평가되었다. Code 505는 해당 검체 에 대해 합의된 결론을 도출할 수 없어 평가할 수 없는 경우이다. 


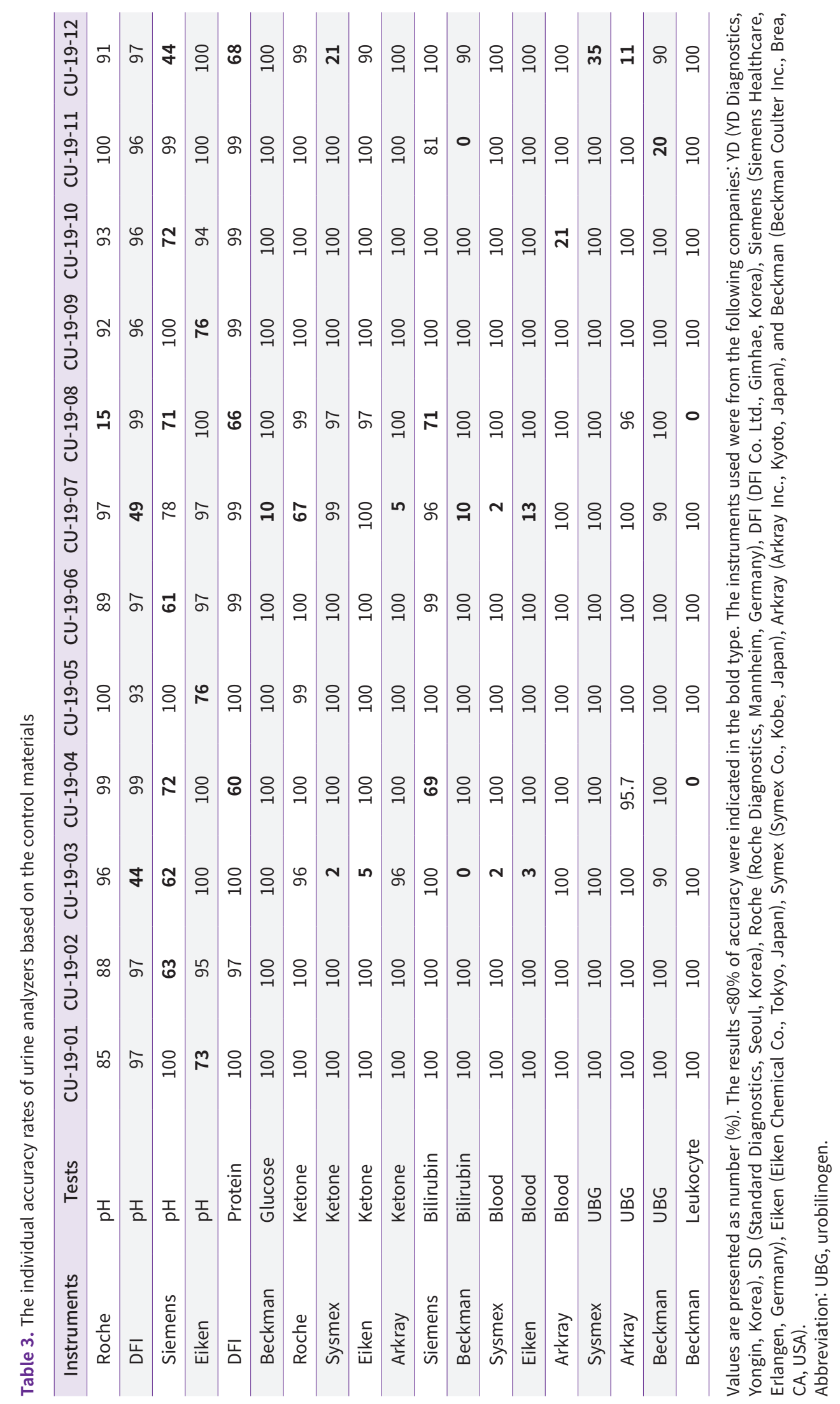


Table 4. Acceptable rates in the urine specific gravity test

\begin{tabular}{llllllc}
\hline Specimen & $\begin{array}{c}\text { No. of } \\
\text { participants }\end{array}$ & Mean \pm SD & Minimum & Maximum & 2.5-97.5 percentiles & $\begin{array}{c}\text { Acceptable } \\
\text { (\%) }\end{array}$ \\
\hline CU-19-01 & 1,517 & $1.005 \pm 0.036$ & 0.01 & 1.07 & $1.000-1.013$ & 97.4 \\
\hline CU-19-02 & 1,517 & $1.007 \pm 0.036$ & 0.01 & 1.02 & $1.005-1.015$ & 99.0 \\
\hline CU-19-03 & 1,517 & $1.004 \pm 0.003$ & 1 & 1.015 & $1.000-1.010$ & 99.5 \\
\hline CU-19-04 & 1,517 & $1.019 \pm 0.037$ & 0.01 & 1.033 & $1.010-1.030$ & 99.3 \\
\hline CU-19-05 & 1,548 & $1.005 \pm 0.036$ & 0.01 & 1.025 & $1.000-1.010$ & 97.5 \\
\hline CU-19-06 & 1,548 & $1.005 \pm 0.003$ & 1 & 1.02 & $1.000-1.010$ & 95.5 \\
\hline CU-19-07 & 1,548 & $1.008 \pm 0.003$ & 1 & 1.025 & $1.005-1.015$ & 99.7 \\
\hline CU-19-08 & 1,547 & $1.019 \pm 0.026$ & 0.015 & 1.032 & $1.010-1.030$ & 99.0 \\
\hline CU-19-09 & 1,555 & $1.004 \pm 0.044$ & 0.01 & 1.225 & $1.000-1.015$ & 99.5 \\
\hline CU-19-10 & 1,555 & $1.007 \pm 0.036$ & 0.01 & 1.025 & $1.005-1.015$ & 97.4 \\
\hline CU-19-11 & 1,555 & $1.006 \pm 0.044$ & 0.01 & 1.06 & $1.003-1.015$ \\
\hline CU-19-12 & 1,555 & $1.023 \pm 0.027$ & 0.025 & 1.3 & $1.015-1.030$ & 97.6 \\
\hline
\end{tabular}

Abbreviation: SD, standard deviation.
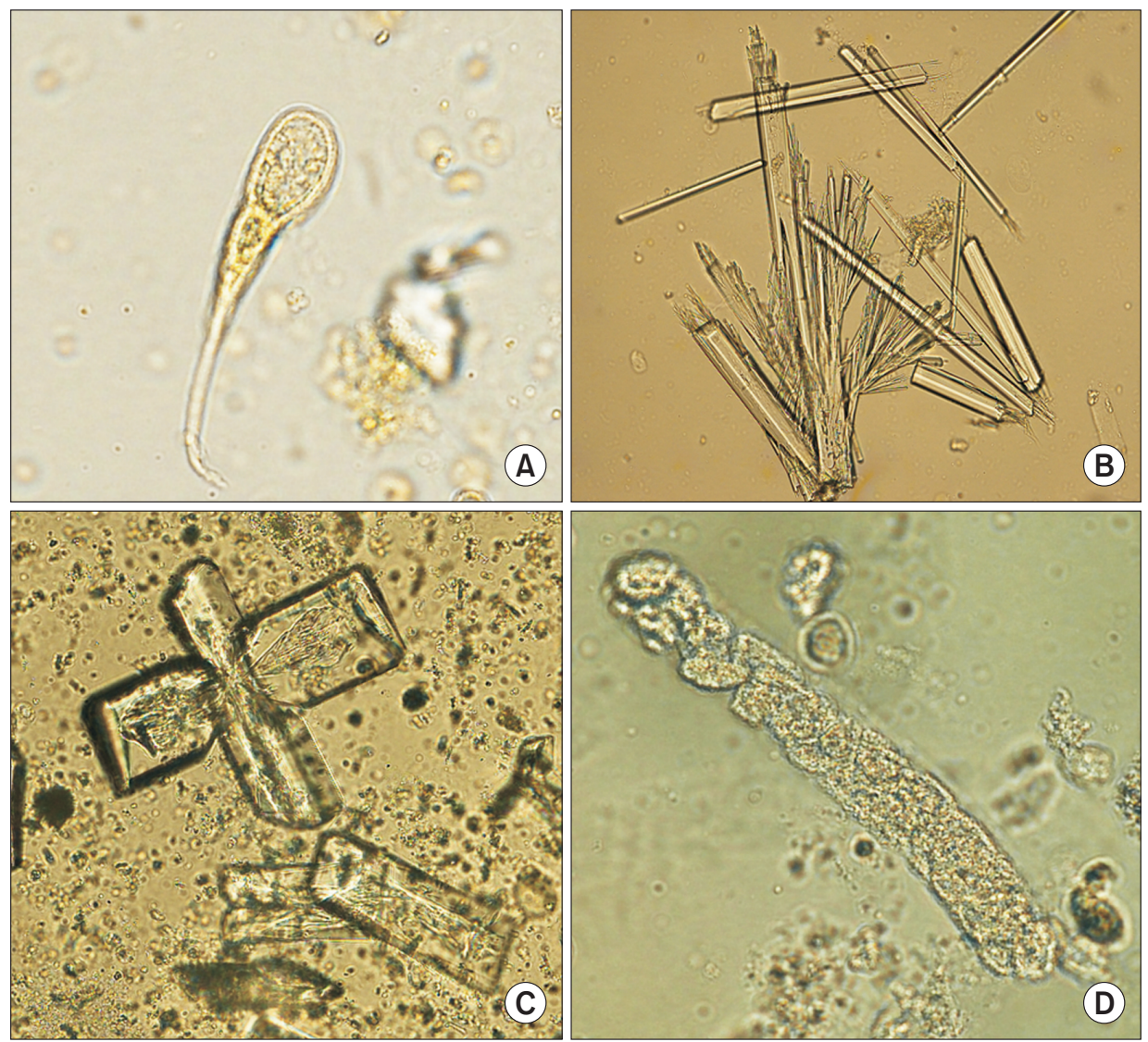

Fig. 1. Images of urine sediments for external quality assessment. (A) CUI-19-01 transitional epithelial cells (original magnification $x$ 400). (B) CUI-19-02 contrast media (original magnification $\times 200$ ). (C) CUI-19-03 ammonium magnesium phosphate (original magnification $\times 400$ ). (D) CUI-19-04 white blood cell cast (original magnification $x$ 400).

\section{FOB 시약에 따른 FOB 정성검사의 정답률 및 시약의 분포}

$\mathrm{FOB}$ 시약에 따른 $\mathrm{FOB}$ 정성검사의 정답률은 Table 6 에 나타내 었다. 시약은 SD FOB rapid test (337기관), YD FOB test (140
기관), Asan FOB easy test (Asan Pharmaceutical, Seoul, Korea; 64기관), Eiken Hemocatch light (42기관) 순으로 사용 하였다. 


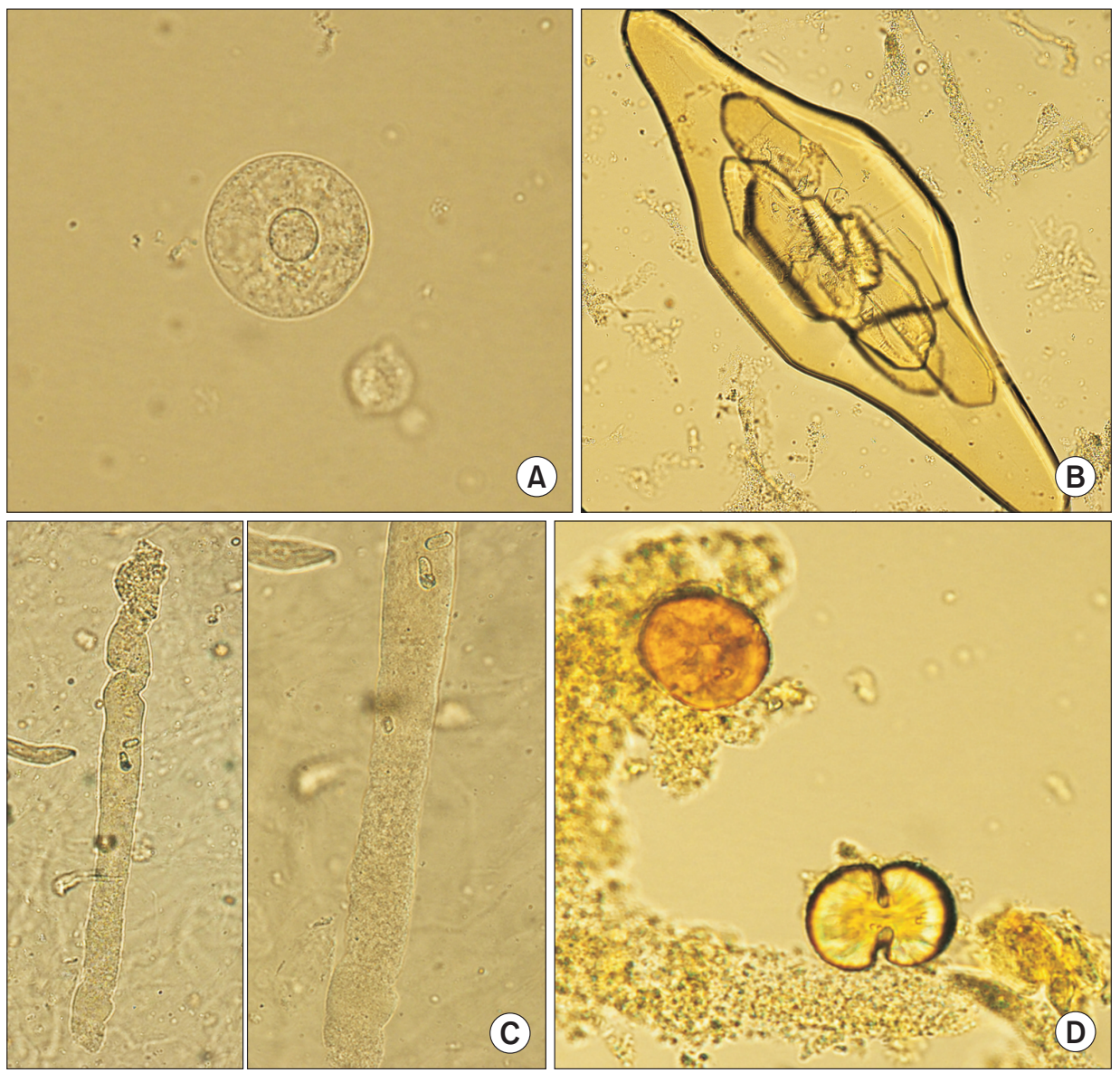

Fig. 2. Images of urine sediments for external quality assessment. (A) CUI-19-05 transitional epithelial cells (original magnification $x$ 400). (B) CUI-19-06 uric acid crystal (original magnification $\times 200$ ). (C) CUI-19-07 broad cast (C1: original magnification $\times 200$; C2: original magnification $\times 400)$. (D) CUI-19-08 calcium oxalate crystals (original magnification $\times 400$ ).
모든 시약에서 양호한 정답률을 나타내었으나, FOB 음성 3검체 중 1 검체에서 SD FOB 시약은 $90 \%$ 이하의 정답률을 나타내었다. 반면, Humasis FOB 시약(Humasis Co., Anyang, Korea)은 양 성 3검체 중 2 검체에서 $90 \%$ 이하의 정답률을 나타내었다.

\section{FOB 시약에 따른 FOB 정량검사의 정답률 및 시약의 분포}

FOB 정량검사결과 분포는 Table 7에 요약하였다. 장비별로 검사에 사용하는 대변량이 달라서 장비 간 비교가 어려워 보정 한 값을 함께 비교하였다. 사용장비는 Eiken (172기관), Alfresa (Alfresa Pharma Co., Osaka, Japan; 64기관), Kyowa (Kyowa Chemical Industry Co., Kagawa, Japan; 36기관) 순으로 분 포하였다. Alfresa 장비는 장비에 따라 결과치가 너무나 상이하여 NS-Plus C와 NS-Prime으로 나누어 분석하였다.

Eiken, Kyowa, Alfresa NS-Prime 장비는 Kyowa 장비가 FOB 양성 검체(CS-19-04, CS-19-06)에서 다소 높은 값을 보였으 나 유사한 결과를 나타내었다. 그러나 Alfresa NS-Plus C 장비는 CS-19-01, CS-19-03 및 CS-19-05 검체에서 매우 높은 수치를 보 였다. 본 검체들은 모두 음성 검체로서 Alfresa NS-Plus C를 사용
하는 기관에서는 양성으로 보고할 수 있었다.

\section{고찰}

2019년 신빙도조사사업에 참여한 기관 수는 1,656 으로 증가율 은 2018년 9.6\%에 비해 다소 낮은 4.0\%의 증가율을 보였다.

신빙도조사 결과를 살펴보면, 요화학검사의 $\mathrm{pH}$ 항목에서 1 차 및 2차 조사의 정답률이 각각 $91.5 \%$ 및 $93.5 \%$ 로 나타났으 며, 그 외의 항목에서는 모두 $95 \%$ 이상의 정답률을 나타내었다. 2018 년에는 $\mathrm{pH}$ 항목이 $90.4 \%$ 의 정답률을 보여 다소 개선된 정 답률을 나타내었다. 장비별로 분석한 요화학검사의 정답률에서 는 $\mathrm{pH}$, glucose, ketone, bilirubin, blood, urobilinogen 및 leukocyte에서 $90 \%$ 이하의 정답률을 나타내는 장비가 발견되었 다. 이와 같이 다수의 항목에서 정답률이 낮아진 것은 반정량 값 의 정답 허용범위를 전체 참여기관의 $80 \%$ 까지 적용하였기 때문 이다. Table 3은 $80 \%$ 이하의 정답률을 보이는 경우를 요약하였 으며, $\mathrm{pH}$ 항목은 11 종의 검체 및 4 종의 분석장비에서 낮은 정답 률을 나타내었다. Ketone은 3종의 검체 및 4종의 분석장비에서, 
Table 5. Acceptable rates in the urine sediments examination

\begin{tabular}{|c|c|c|c|c|c|c|c|}
\hline Specimen no. & $\begin{array}{l}\text { No. of } \\
\text { partici- } \\
\text { pants }\end{array}$ & Results & $\begin{array}{c}\text { No. of } \\
\text { answers }\end{array}$ & $\begin{array}{c}\% \\
\text { Accept- } \\
\text { able }\end{array}$ & $\begin{array}{l}\% \text { Un- } \\
\text { accept- } \\
\text { able }\end{array}$ & $\begin{array}{l}\text { Correct } \\
\text { answer }\end{array}$ & Decision \\
\hline CUI-19-01 & 895 & Transitional epithelial cell & 832 & 93.0 & & 0 & \\
\hline CUI-19-01 & 895 & Spermatozoa & 25 & & 2.8 & & \\
\hline CUI-19-01 & 895 & Renal tubular epithelial cell & 23 & & 2.6 & & \\
\hline CUI-19-02 & 895 & Calcium phosphate & 404 & 45.1 & & & Code505 \\
\hline CUI-19-02 & 895 & Sodium urate & 296 & 33.1 & & & Code505 \\
\hline CUI-19-02 & 895 & Contrast media & 63 & 7.0 & & o & Code505 \\
\hline CUI-19-03 & 895 & Ammonium magnesium phosphate & 783 & 87.5 & & o & \\
\hline CUI-19-03 & 895 & Calcium phosphate & 65 & & 7.3 & & \\
\hline CUI-19-03 & 895 & Amorphous urates/phosphates & 23 & & 2.6 & & \\
\hline CUI-19-04 & 895 & Granular cast & 486 & 54.3 & & & Code505 \\
\hline CUI-19-04 & 895 & White blood cell cast & 178 & 19.9 & 19.9 & o & Code 505 \\
\hline CUI-19-04 & 895 & Cellular cast & 134 & 15.0 & 15.0 & & Code505 \\
\hline CUI-19-05 & 917 & Transitional epithelial cell & 577 & 62.9 & & o & Code505 \\
\hline CUI-19-05 & 917 & Renal tubular epithelial cell & 289 & & 31.5 & & Code505 \\
\hline CUI-19-05 & 917 & Squamous epithelial cell & 39 & & 4.3 & & Code505 \\
\hline CUI-19-06 & 917 & Uric acid & 906 & 98.8 & & 0 & \\
\hline CUI-19-06 & 917 & Sodium urate & 5 & & 0.5 & & \\
\hline CUI-19-06 & 917 & Ammonium biurate & 3 & & 0.3 & & \\
\hline CUI-19-07 & 917 & Hyaline cast & 622 & & 67.8 & & Code505 \\
\hline CUI-19-07 & 917 & Waxy cast & 142 & 15.5 & & & Code505 \\
\hline CUI-19-07 & 917 & Broad cast & 130 & 0.4 & & 0 & Code505 \\
\hline CUI-19-08 & 917 & Calcium oxalate & 842 & 91.8 & & o & \\
\hline CUI-19-08 & 917 & Calcium carbonate & 56 & & 6.1 & & \\
\hline CUI-19-08 & 917 & Leucine & 9 & & 1.0 & & \\
\hline
\end{tabular}

blood 항목은 3종의 검체 및 3종의 분석장비에서, urobilinogen 은 2종의 검체 및 3 종의 분석장비에서 각각 낮은 정답률을 나타내 었다. 특히 $50 \%$ 이하의 정답률을 나타내는 경우는 정도관리 검체 에 따라 장비별로 기질효과가 발생하는 것으로 보인다[1]. 한편, Beckman사의 백혈구 항목은 1차 및 2차 신빙도조사에서는 $0 \%$ 의 정답률을 나타내었으나, 3 차 신빙도조사에서는 $100 \%$ 의 정답 률을 보였다.

요비중검사는 2018년과 성적과 동일하게 참여기관의 정답률이 양호하였으나 아직도 결과 입력오류가 발견되었다. 매일 환자의 결과를 입력하는 것처럼 정도관리 결과 입력도 정도관리의 한 부 분이다. 따라서 비정상적인 결과가 입력되지 않도록 각 기관에서 는 각별한 주의를 기울여야 할 것이다.

요침사 신빙도조사에서는 총 8 개의 검체 중 4 개의 검체에서 code 505가 적용되었다. 2019년에는 contrast media, 백혈구 원주, 광폭원주 등 다소 난이도가 높은 결정체들이 제시되어 정답 률이 낮아진 것으로 생각되었다.

백혈구 원주는 임상 검체에서 자주 나타나는 침사물이므로 각 기관에서 좀더 주의를 기울여 잘 판독할 수 있어야 할 것이다. 광 폭원주를 $67.8 \%$ 에서 초자원주로 보고하였는데, 이 두 개의 원주 는 반드시 구분할 수 있어야 한다. 광폭원주는 신부전 환자에서 관 찰되며[2], 기질이 두껍고, 원주의 주변이 뚜렷하다는 점에서 초 자원주와 감별된다[3]. 반면, 초자원주는 정상뇨에서 관찰되는 데, 무색이고 투명하며 둥근 말단부를 보인다[4]. 방사선 조영물 질은 hypaque sodium (diatrizoate meglumine)을 주로 사용 하며 정맥주사 후 소변에서 3일까지 관찰될 수 있다[4]. Calcium phosphate 및 sodium urate 등과 육안으로 구별이 용이하지 
Table 6. Acceptable rates in the fecal occult blood quality test

\begin{tabular}{lcccccccc}
\hline \multicolumn{1}{c}{ Reagents } & $\begin{array}{c}\text { Specimen } \\
\text { (intended } \\
\text { response) }\end{array}$ & $\begin{array}{c}\text { CS-19-01 } \\
\text { (negative) }\end{array}$ & $\begin{array}{l}\text { CS-19-02 } \\
\text { (positive) }\end{array}$ & $\begin{array}{c}\text { CS-19-03 } \\
\text { (negative) }\end{array}$ & $\begin{array}{r}\text { Specimen } \\
\text { (intended } \\
\text { response) }\end{array}$ & $\begin{array}{c}\text { CS-19-04 } \\
\text { (positive) }\end{array}$ & $\begin{array}{c}\text { CS-19-05 } \\
\text { (negative) }\end{array}$ & $\begin{array}{c}\text { CS-19-06 } \\
\text { (positive) }\end{array}$ \\
\hline SD FOB rapid test & 337 & $\mathbf{8 8 . 4}$ & 99.7 & 99.4 & 343 & 100.0 & 98.0 & 99.1 \\
\hline YD Occult Tech FOB test & 140 & 99.3 & 98.6 & 99.3 & 148 & 100.0 & 98.6 & 100.0 \\
\hline ASAN rasy test FOB & 64 & 96.9 & 98.4 & 98.4 & 65 & 98.5 & 93.9 & 98.5 \\
\hline Eiken Hemocatch light & 42 & 100.0 & 100.0 & 100.0 & 40 & 100.0 & 100.0 & 97.5 \\
\hline Humasis FOB test & 39 & 97.4 & 89.7 & 97.4 & 38 & 92.7 & 97.6 & $\mathbf{8 2 . 9}$ \\
\hline HBI HiSens FOB NCard & 32 & 100.0 & 100.0 & 100.0 & 28 & 100.0 & 100.0 & 100.0 \\
\hline GC Genedia FOB & 25 & 96.0 & 100.0 & 100.0 & 27 & 100.0 & 100.0 & 100.0 \\
\hline Bio Focus FOB rapid test & 20 & 95.0 & 100.0 & 100.0 & 17 & 100.0 & 100.0 & 94.1 \\
\hline
\end{tabular}

Values are presented as number of participants or acceptable \%, unless otherwise stated. The results $<90 \%$ of accuracy were indicated in the bold type. The instruments used were from the following companies: SD (Standard Diagnostics, Seoul, Korea), YD (YD Diagnostics, Yongin, Korea), Asan Pharmaceutical (Seoul, Korea), Eiken Chemical Co. (Tokyo, Japan), Humasis Co. (Anyang, Korea), HBI Co. (Anyang, Korea), GC (Green Cross Medial Science Co., Yongin, Korea), and Bio Focus Co. (Uiwang, Korea).

Abbreviation: FOB, fecal occult blood.

Table 7. Result distribution of fecal occult blood quantitative test

\begin{tabular}{|c|c|c|c|c|c|c|c|c|}
\hline \multirow{2}{*}{ Instruments } & \multirow{2}{*}{ Specimen no. } & \multirow{2}{*}{ No. } & \multicolumn{3}{|c|}{$\mathrm{ng} / \mathrm{mL}$} & \multicolumn{3}{|c|}{$\mu \mathrm{g} / \mathrm{g}$ stool } \\
\hline & & & Mean & Minimum & Maximum & Mean & Minimum & Maximum \\
\hline Eiken & CS-19-01 & 164 & 8.5 & 0.0 & 25.0 & 1.7 & 0.0 & 5.0 \\
\hline Kyowa & CS-19-01 & 42 & 0.5 & 0.0 & 2.0 & 0.5 & 0.0 & 2.0 \\
\hline Alfresa NS-Prime & CS-19-01 & 45 & 6.7 & 0.0 & 17.0 & 1.3 & 0.0 & 3.2 \\
\hline Alfresa NS-Plus C & CS-19-01 & 22 & 74.5 & 40.0 & 91.0 & 14.2 & 7.6 & 17.3 \\
\hline Eiken & CS-19-02 & 164 & 314.4 & 102.0 & 478.0 & 62.9 & 20.4 & 95.6 \\
\hline Kyowa & CS-19-02 & 42 & 75.8 & 17.0 & 109.0 & 75.8 & 17.0 & 109.0 \\
\hline Alfresa NS-Prime & CS-19-02 & 45 & 252.0 & 172.0 & 302.0 & 47.9 & 32.7 & 57.4 \\
\hline Alfresa NS-Plus C & CS-19-02 & 22 & 253.5 & 132.0 & 343.0 & 48.2 & 25.1 & 65.2 \\
\hline Eiken & CS-19-03 & 164 & 5.0 & 0.0 & 14.0 & 1.0 & 0.0 & 2.8 \\
\hline Kyowa & CS-19-03 & 42 & 0.1 & 0.0 & 1.0 & 0.1 & 0.0 & 1.0 \\
\hline Alfresa NS-Prime & CS-19-03 & 45 & 4.3 & 0.0 & 12.0 & 0.8 & 0.0 & 2.3 \\
\hline Alfresa NS-Plus C & CS-19-03 & 22 & 80.0 & 47.0 & 101.0 & 15.2 & 8.9 & 19.2 \\
\hline Eiken & CS-19-04 & 172 & 364.6 & 14.0 & 537.0 & 72.9 & 2.8 & 107.4 \\
\hline Kyowa & CS-19-04 & 37 & 89.9 & 35.0 & 166.0 & 89.9 & 35.0 & 166.0 \\
\hline Alfresa NS-Prime & CS-19-04 & 45 & 266.4 & 19.0 & 319.0 & 54.8 & 43.7 & 69.2 \\
\hline Alfresa NS-Plus C & CS-19-04 & 21 & 288.2 & 230.0 & 364.0 & 54.8 & 43.7 & 69.2 \\
\hline Eiken & CS-19-05 & 172 & 6.9 & 0.0 & 78.0 & 1.4 & 0.0 & 15.6 \\
\hline Kyowa & CS-19-05 & 37 & 0.2 & 0.0 & 2.0 & 0.2 & 0.0 & 2.0 \\
\hline Alfresa NS-Prime & CS-19-05 & 45 & 5.7 & 0.0 & 13.0 & 1.1 & 0.0 & 2.5 \\
\hline Alfresa NS-Plus C & CS-19-05 & 21 & 76.2 & 21.0 & 94.0 & 14.5 & 4.0 & 17.9 \\
\hline Eiken & CS-19-06 & 172 & 134.3 & 5.0 & 191.0 & 26.9 & 1.0 & 38.2 \\
\hline Kyowa & CS-19-06 & 37 & 38.9 & 8.0 & 64.0 & 38.9 & 8.0 & 64.0 \\
\hline Alfresa NS-Prime & CS-19-06 & 45 & 101.2 & 9.0 & 143.0 & 19.2 & 1.7 & 27.2 \\
\hline Alfresa NS-Plus C & CS-19-06 & 21 & 131.7 & 113.0 & 186.0 & 25.0 & 21.5 & 35.3 \\
\hline
\end{tabular}

The instruments used were from the following companies: Eiken Chemical Co. (Tokyo, Japan), Kyowa Chemical Industry Co. (Kagawa, Japan), NS-Plus C, and NS-Prime (Alfresa Pharma Co., Osaka, Japan). 
는 않지만 산성뇨에서 생성되고 $10 \% \mathrm{NaOH}$ 에서 용해되어 감별 할 수 있다[2]. 이행상피세포의 정답률은 2018년 55.2\%에 비하여 $62.9 \%$ 및 $93.0 \%$ 로 많이 개선되었다[5].

FOB 정성검사에서는 2018년에 이어 2019년에도 음성 검체에 대한 위양성률이 높지 않아, 개선된 국내 시약의 품질이 유지되고 있는 것으로 보인다[5]. SD사 시약은 음성 검체에 대한 가장 낮은 정답률이 $88.4 \%$ 였는데, 이는 2018년의 가장 낮은 정답률 $76.4 \%$ 에 비해 많이 개선된 결과이다[5]. 반면, Humasis사 시약은 2개의 양성 검체에서 $90 \%$ 이하의 정답률을 보여 주의가 필요하였다.

대변잠혈 정량검사에서 Alfresa 장비의 두 가지 모델의 농도차 가 현저하여, Alfresa 장비는 모델별로 분리하여 정답분포를 분석
하였다. Alfresa NS-Plus C 장비는 음성 검체에서 모두 높은 수 치를 나타내었으나, FOB 양성 검체에서는 Alfresa NS-Prime 장 비 및 Eiken 장비와 유사한 농도값을 나타내었다. 따라서 Alfresa NS-Plus C 장비는 대변정량검사에서 위양성 결과를 도출할 가 능성이 높다. NS-Plus C는 2018년도에 27개 기관에서 사용하 였으나[5], 2019년 22개 기관이 사용하여 감소하였고, 대신 NSPrime의 사용이 37 개 기관에서 45 개 기관으로 증가하여 바람직 한 변화를 보였다. Kyowa 장비는 2018년과 유사하게 양성 검체 에서 다소 높게 측정되는 경향을 보였다. Table 7 에 제시된 $\mu \mathrm{g} / \mathrm{g}$ stool에 의한 수치는 실제치가 아니고 장비별로 주입되는 대변 양 을 일괄적으로 적용하여 산술적으로 도출된 수치이다.

\section{REFERENCES}

1. Jeon CH, Lee AJ, Kim SG, Suh HS, Bae YC. Annual report on the external quality assessment scheme for urinalysis and fecal occult blood testing in Korea (2017). J Lab Med Qual Assur 2018;40:128-35.

2. Karcher DS, McPherson RA. Cerebrospinal, synovial, serous body fluids, and alternative specimens. In: McPherson RA, Pincus MR, editors. Henry's clinical diagnosis and management by laboratory methods. 23rd ed. St. Louis (MO): Elsevier, 2017:467-8.

3. Itoh K, Miyachi H, Asai S, Nozaki T. Atlas of urinary sediment. Kobe: Sysmex Co., 2014.

4. Mundt LA, Shanahan K. The urinalysis. In: Mundt LA, Shanahan K. Graff's textbook of urinalysis and body fluids. 3rd ed. Philadelphia (PA): Wolters Kluwer, 2016:125-32.

5. Jeon CH, Lee AJ, Kim SG, Suh HS, Bae YC. Annual report of the Korean Association of External Quality Assessment Service on urinalysis and fecal occult blood testing (2018). J Lab Med Qual Assur 2019;41:75-81. 